level, there are more fundamental questions about ecosystem dynamics that paleo-data may help to address, for example:

- What can we learn about the dynamics of ecosystems which include, and in many cases are dominated by long-lived taxa?

- Is it possible to use the paleo-record to develop generalizations regarding the nature of ecological thresholds and non-linear changes?

- In so far as future climate scenarios for given ecosystems are sufficiently similar to past conditions, what does the paleo-record tell us with regard to survival and persistence at species, patch and landscape levels?

- In environments where long term succession is likely to influence future ecosystems, what does the paleo-record tell of successional processes, rates and trends?

- Where the periodicity/mean recurrence interval of extreme events or disturbance regimes is decadal or longer, what insights do paleo-data give on frequencies, impacts and interactions?

- What do studies with high temporal resolution during and after ear- lier periods of rapid environmental change tell us about rates of biotic response?

- In light of all the above, how can the paleo-record best interact with ecosystem modeling?

\section{Scientific Contexts and Case-study Inte- gration}

The above questions cover a wide range of environmental contexts and research agendas and will be addressed mainly through site-specific case-studies leading where possible to generalizations about generic properties of particular sets of ecosystems

There is now an urgent need for us to select exemplary case-studies that have general significance for generating and testing hypotheses, that are likely to provide answers to important ecological questions and that represent extensive, valued or vulnerable ecosystems. In addition, there is an equally urgent need for a series of shared goals, priorities, criteria and research protocols that will provide an integrative framework for the case studies undertaken. HITE proposes to hold an initial Workshop in Spring 2001 to begin the process of articulating and developing the necessary research agenda. We envisage, at this stage, a group of around 20 colleagues representing key case studies which we propose to unite into a coherent research framework through the definition and adoption of common goals, priorities, criteria and protocols.

\section{Frank Oldfield}

PAGES IPO, Bern, Switzerland

frank.oldfield@pages.unibe.ch

\section{John A. Dearing}

Department of Geography, University of Liverpool, UK i.dearing@liverpool.ac.uk

\section{Marie-José Gaillard}

School of Biosciences and Process Technology, Växiö University, Sweden

marie-jose.gaillard-lemdah|@ibp.vxu.se

\section{Harald Bugmann}

Mountain Forest Ecology, Department of Forest Sciences, Swiss Federal Institute of Technology Zurich, Switzerland

bugmann@fowi.ethz.ch

\section{RefERENCES}

Oldfield, F. (1983) Man's impact on the environment: some recent perspectives. Geography, 68, 245 256.

Roberts, N. (1989;1998). The Holocene. (Editions 1 and 2), Blackwell, Oxford.

\title{
Using History To Interpret Current Environmental Conditions and Future Trends: An Example from the US Long Term Ecological Research (LTER) Program
}

Acknowledgement of the value of a historical framework for modern studies has led major US agencies including the Forest Service and National Park Service to employ a wide range of retrospective approaches to define historical ranges of variability in landscape patterns and ecosystem structure and function as a basis for conservation and natural resource planning. Similarly, the 25 sites in the US National Science Foundation's Long Term Ecological Research (LTER) Program increasingly emphasize historical research involving scientists from diverse social and physical disciplines. Examples from the Harvard Forest LTER site in Massachusetts underscore the essential contribution of history to environmental research and planning. Importantly, historical studies figure into all aspects of this research program, from interpreting modern vegetation patterns and developing ecological restoration strategies to projecting the future role of temperate forests in the global carbon balance to anticipating forest response to atmospheric nitrogen deposition.

Like all of the New England states and much of the eastern US, Massachusetts has undergone a remarkable transformation over the past 300 years ${ }^{11}$. Following European settlement in the $17^{\text {th }}-18^{\text {th }}$ centuries, land was increasingly cleared for agriculture into the mid $19^{\text {th }} \mathrm{C}$ when $70 \%$ was open pasture and arable land and the remainder was largely coppice stands and woodlots. With industrialization and the development of mid-western agriculture in the $19^{\text {th }}$ C, New England farmland was abandoned and the rural popula- tion joined a rapidly growing immigrant population in cities, industrial towns, and, more recently, the suburbs ${ }^{23}$. Neglected farmland reforested naturally, and with wood products increasingly supplied from elsewhere, tree size, forest age, and wood biomass are on an upward trajectory. New England is currently $50-90 \%$ forested $^{12}$.

Although ecosystem studies in the eastern US have generally proceeded with little consideration of historical factors, Harvard Forest research underscores the message that incorrect interpretations occur without a detailed knowledge of changing landscape conditions and environmental drivers over past centuries or millennia ${ }^{14}$. At a local scale, forest composition and structure in New England are strongly linked to prior use of sites as for example, pas- 
ture, tilled land, or continuous woodland $^{21,22}$. Site land-use histories are also clearly visible in the physical (e.g. horizonation) and biogeochemical (e.g. C:N ratios, $\mathrm{N}$ cycling) characteristics of the modern soil ${ }^{7,8}$. Such legacies of past land use persist despite more than a century of forest development and subsequent disturbances (e.g. intensive logging, hurricane, or fire) ${ }^{22}$. Interestingly, many aquatic parameters exhibit equivalent "memories" of past landscape conditions ${ }^{15}$. For example, sediment characteristics (e.g., organic content, C:N ratio) that changed dramatically as the catchments were deforested and farmed have remained largely unchanged over the past 150 years as the watersheds reforested. Paleoecological studies, which provide a unique ability to evaluate the entire sequence of changes from the pre-European period to the present, repeatedly show that for terrestrial and aquatic ecosystems alike the past continues to condition the present, modern conditions are unique, and there is little tendency to return to antecedent conditions ${ }^{9,13}$

At a broader scale (e.g., $5000 \mathrm{~km}^{2}$ ) forest composition is relatively homogeneous across substantial physiographic and climatic gradients ${ }^{12}$. Historical and paleoecological investigations confirm that this homogeneity is only centuries old and is largely a product of the relatively homogeneous human disturbance regime. Indeed, at the time of European settlement $\left(17^{\text {th }} \mathrm{C}\right)$ tree species distributions were closely related to growing season length. However, pollen studies from a network of sites indicate that land use is not the sole driver of this historical change ${ }^{16}$. Rather, over the past millennium high rates of vegetation change were initiated during the Little Ice Age (ca. 1450-1850 AD). In fact, the major compositional change previously attributed to historical land use the decline of beech and hemlock - may have been largely a lagged response in populations already declining due to prior climate change. Clearly, the modern landscape is a complex product of past environments and multiple disturbances that can only be deciphered through many long views through time ${ }^{19}$.

Lagging behind, but largely driven by the changing land cover and land use across the northeastern US has been a

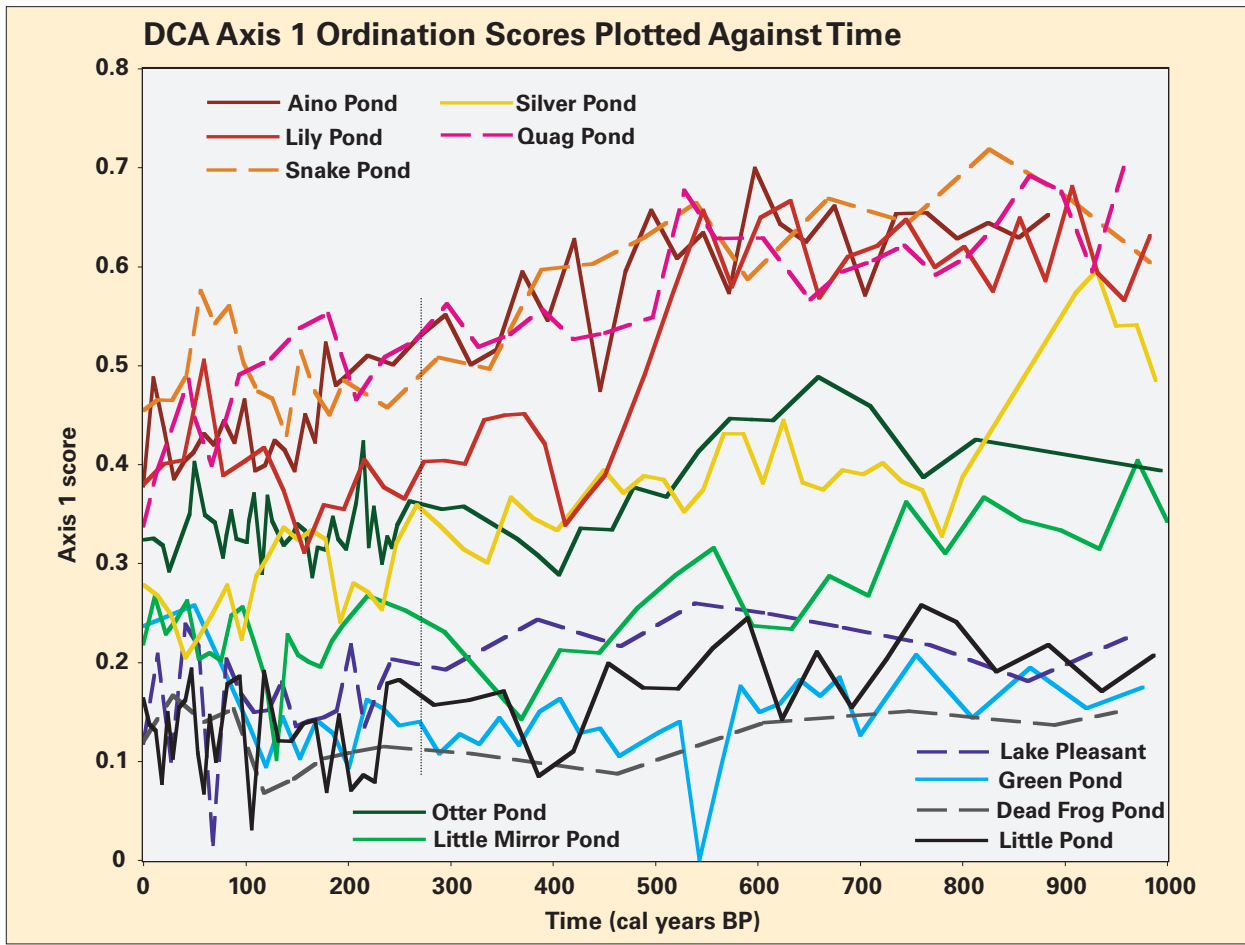

Figure 1: Long-term changes in forest composition in central New England USA, depicted through DCA (detrended correspondence analysis) scores for 11 pollen diagrams from small lakes. The lakes are distributed across a regional climate gradient of approximately $2^{\circ} \mathrm{C}$ in lowland (blue, green and black) and upland (red and yellow) areas. Major changes and regional homogenization in forest composition occurred after European settlement (vertical line, ca. 1725 AD). However, these historical changes were part of a longer-term trend driven by climate change coincident with the Little Ice Age. Separating human and environmental drivers of forest change requires a millennial perspective. From Fuller et al. 1998.

recent transformation in wildlife populations that poses major challenges for conservation, wildlife management, and public health and safety ${ }^{10}$. Notably, widespread and common plants and animals from the cultural agrarian landscape of the $19^{\text {th }}$ century are becoming uncommon and are emerging as conservation priorities, whereas many larger mammals, birds, and fish, which were extirpated or reduced following European settlement, are spreading and thriving. With changes in land cover and species come threats to humans from: diseases facilitated by animal hosts or insects that thrive in the new environment (e.g., Lyme disease, giardia, equine encephalitis, West Nile Virus), vehicular or backyard encounters with wildlife (moose, bear, coyotes, deer), or the indirect activity of animals such as beaver. Understanding these wildlife and pathogen dynamics, educating the public, and managing the land and organisms require an understanding of centuries of landscape and human history. Whether and how to maintain species of cultural landscapes and how to manage the wide-ranging larger species are major policy issues rooted in history ${ }^{4}$.

History also figures into emerging regional and global stories concerning nitrogen and carbon dynamics. High rates of atmospheric nitrogen inputs have resulted from fossil fuel combustion in industrialized regions of North America and Europe. Major questions loom regarding the ability of forest ecosystems to store this limiting resource, thereby mitigating its impact on aquatic systems and human health, and the effect of these inputs on forest ecosystem health ${ }^{3}$. Recently, major hypotheses regarding "nitrogen saturation" have been revised to incorporate historical effects and legacies as a consequence of unexpected results ${ }^{2,3}$. Field measurements and long-term experiments indicate that ecosystem history (e.g., past cutting, fire, agriculture) plays a critical role in determining initial site conditions regarding $\mathrm{N}$ availability and the potential for $\mathrm{N}$ uptake. In particular, land use over past centuries may be more important than modest regional differences in $\mathrm{N}$ deposition or forest type in determining current nitrogen 
status and forest susceptibility to N saturation.

Finally, recent evidence suggests that the young (predominantly $<100$ years old) forests of eastern North American are an important global sink for atmospheric $\mathrm{CO}_{2}{ }^{17}$. Long-term eddy flux measurements at the Harvard Forest document an average uptake of 2 tons $C$ per hectare per year and lead to an estimate of a world-wide temperate forest storage of $\pi$ to $\Pi$ Gtons ( 0.25 to 0.50 billion metric tons) $\mathrm{C}$ per year ${ }^{18,24}$. Derivation and interpretation of this estimate and all predictions of future carbon dynamics for temperate forests must necessarily be grounded in a detailed understanding of the disturbance history of these landscapes.

Environmental studies and the agencies that support them and apply their results have demonstrated an increasing reliance on historical studies ${ }^{19}$. Although this interest is partly based on the fundamental insights that come from examining lengthy ecological processes and rare events unfolding through the past, it is ultimately grounded in a much more immediate consideration: an understanding of past conditions and historical legacies improves our interpretation of modern conditions and projections of future states and thereby places our policies on more solid footing $5,6,9$. In the absence of a detailed historical context our analyses will be incomplete and our management solutions often misguided.

\section{DAVId R. Foster}

Harvard Forest, Harvard University, Petersham, MA, USA

drfoster@fas.harvard.edu

For full references please consult www.pagesigbp.org/products/newsletters/ref2003.html

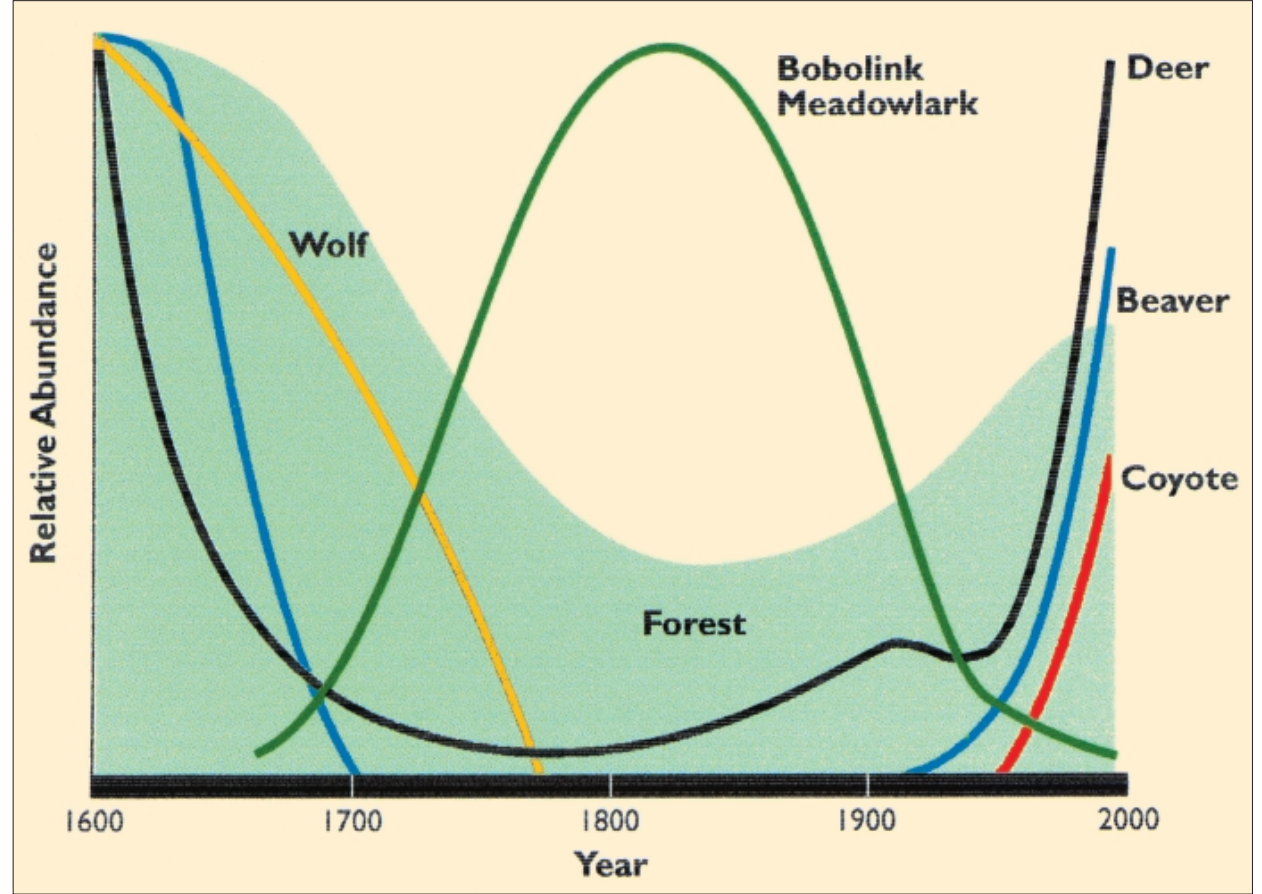

Figure 2: Changes in relative wildlife abundance in the northeastern USA linked to changes in forest cover since AD 1600.

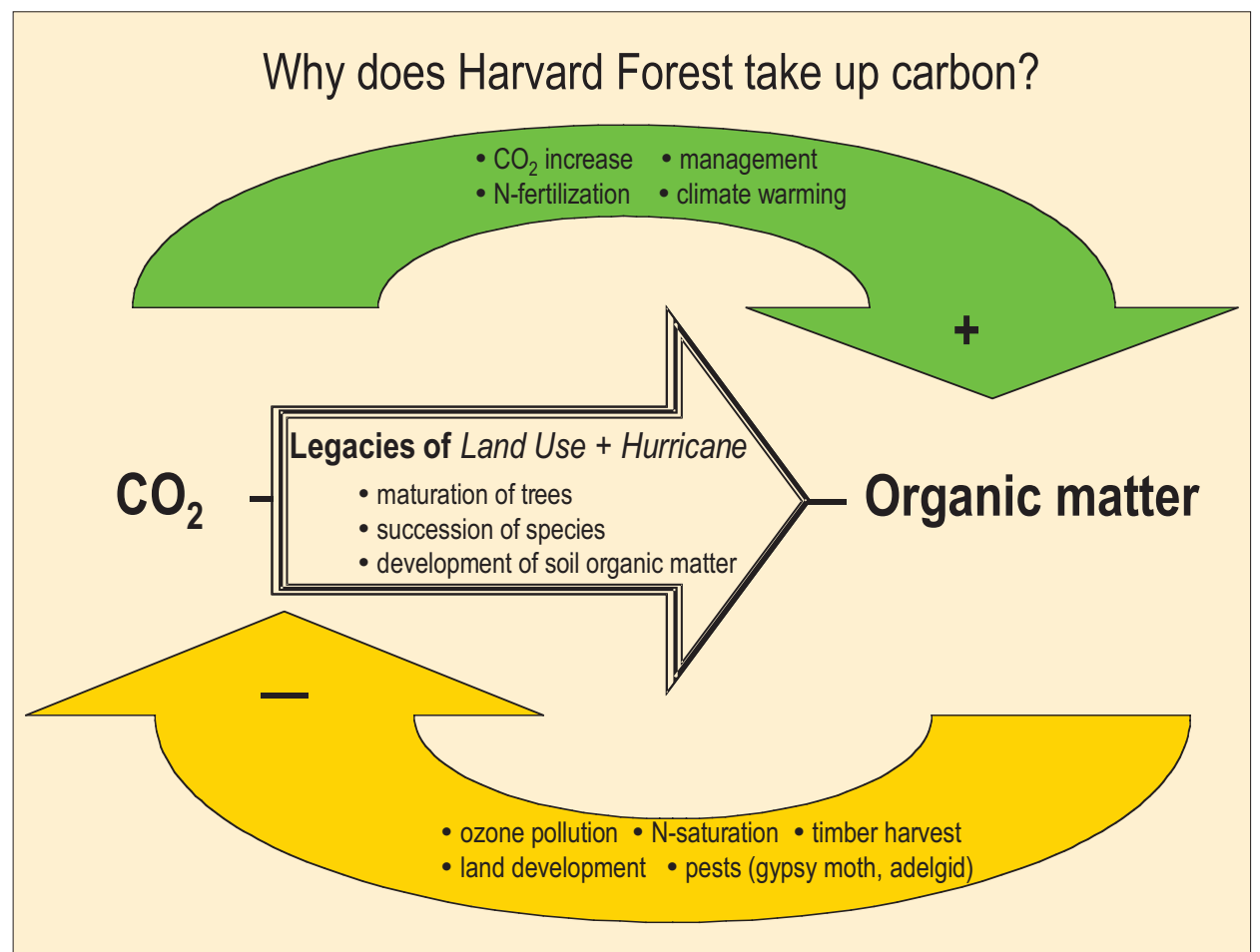

Figure 3: Controls on uptake and release of $\mathrm{CO}_{2}$ at Harvard Forest. The major driving force is recovery from prior agricultural land use and disturbance by the hurricane of 1938 . The rate of uptake is modulated by numerous environmental factors. Factors promoting sequestration or inhibiting decay of organic matter are placed in the upper arrow, others inhibiting sequestration or promoting oxidati on of organic matter are placed in the lower arrow (From S. Wofsy, in press). 